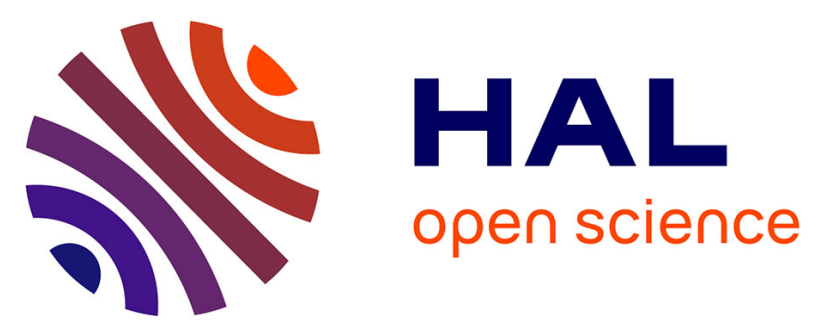

\title{
Frontal weld lines in injection-molded short fiber-reinforced PBT: Extensive microstructure characterization for mechanical performance evaluation
}

Mohamed Besher Baradi, Camilo Cruz, Thomas Riedel, Gilles Régnier

\section{- To cite this version:}

Mohamed Besher Baradi, Camilo Cruz, Thomas Riedel, Gilles Régnier. Frontal weld lines in injectionmolded short fiber-reinforced PBT: Extensive microstructure characterization for mechanical performance evaluation. Polymer Composites, 2019, 40 (12), pp.4547-4558. 10.1002/pc.25310 . hal02539693

\section{HAL Id: hal-02539693 \\ https://hal.science/hal-02539693}

Submitted on 10 Apr 2020

HAL is a multi-disciplinary open access archive for the deposit and dissemination of scientific research documents, whether they are published or not. The documents may come from teaching and research institutions in France or abroad, or from public or private research centers.
L'archive ouverte pluridisciplinaire HAL, est destinée au dépôt et à la diffusion de documents scientifiques de niveau recherche, publiés ou non, émanant des établissements d'enseignement et de recherche français ou étrangers, des laboratoires publics ou privés. 


\title{
Frontal weld lines in injection-molded short fiber-reinforced PBT: Extensive microstructure characterization for mechanical performance evaluation
}

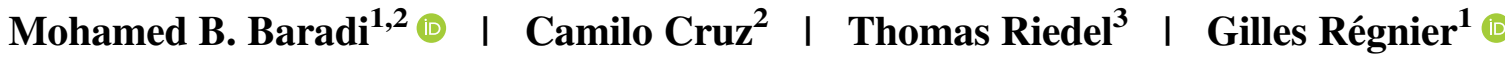

${ }^{1}$ PIMM, ENSAM, CNRS, CNAM, Paris, France

${ }^{2}$ Plastics Engineering, Robert Bosch GmbH, Corporate Sector Research and Advance Engineering, Renningen, Germany

${ }^{3}$ Analytics, Robert Bosch GmbH, Corporate Sector Research and Advance Engineering,

Renningen, Germany

Correspondence

Gilles Régnier, Arts et Métiers ParisTech, PIMM, 151 bd de l'Hôpital, 75013 Paris,

France.

Email: gilles.regnier@ensam.eu

\begin{abstract}
Different factors contribute to the weakness of weld lines (WLs) induced by injection molding such as unsuitable fiber orientation (FO), incomplete polymer matrix diffusion, voids and V-notches. This study aims to characterize the contribution of each factor on the weakness of frontal WLs in a short glass fiber-reinforced polybutylene-terephthalate characterized by extensive $\mathrm{X}$-ray computed tomography and mechanical tensile testing assisted with digital image correlation. A reduction of $50 \%$ of the stress at break and almost $40 \%$ of the strain at break is observed despite the complete matrix healing at the WL interface and the absence of V-notches. Frontal WLs induce a FO gradient starting 2 to $3 \mathrm{~mm}$ before the WL plane. The fibers in the WL region mainly orient in transverseto-flow and thickness direction. This FO gradient localizes the deformations, which leads to failure at a strength near to the one of the unreinforced variant. Voids formation in frontal WLs seems to be driven by large gradients of FO and subsequent anisotropic shrinkage. In addition, this shrinkage behavior at the WL causes an increase of thickness. By applying higher packing pressures, the fibers orient more in flow direction at the core of the WL, leading to a higher tensile strength and a lower content of voids. Finally, we can conclude that the FO is the dominant factor controlling the mechanical performance in frontal WLs.
\end{abstract}

\section{K E Y W O R D S}

injection molding, mechanical properties, microstructure, $\mathrm{X}$-ray, orientation

\section{1 | INTRODUCTION}

Weld line (WL) formation during the injection molding of thermoplastic parts is unavoidable. WLs form when separate polymer flow fronts meet during injection. Multiple flow fronts can appear due to multiple injection gates, inserts inside the mold cavity or pins. ${ }^{[1]}$ We can distinguish between two kinds of WLs:

1. Frontal WLs: Melt fronts meet and stagnate simultaneously.

2. Flowing WLs: Melt fronts meet and then flow through the mold.
Frontal WLs induce a significant reduction on the mechanical properties (quasi-static tensile strength and failure strain) that can reach up to $50 \%$, especially with short fiber-reinforced polymers. Several phenomena can explain the negative influence of WLs on the mechanical properties at failure under quasi-static tensile loading ${ }^{[1-11]}$ :

1. Incomplete molecular diffusion (insufficient polymer matrix healing): Rapid cooling rates in injection molding might give the molecules less time than required to reptate and reach the entanglement density of the bulk polymer. 
2. Fiber orientation $(F O)$ gradient: At the WL, the fibers orient preferentially parallel to the WL surface, reducing the fiber strengthening of the composite when loading in the normal direction of the WL surface.

3. Molecular orientation: Similar to the fibers, the polymer molecules will also orient parallel to the WL surface due to an elongational flow induced by the fountain flow at front. ${ }^{[12]}$ However, the influence of molecular orientation on strength reduction in short fiber-reinforced thermoplastics is nearly negligible. ${ }^{[8]}$

4. V-notches and voids: Both act as stress concentrators at the WL, but their influence can be limited using ventilation channels and by controlling process parameters, especially packing (holding) pressure. ${ }^{[9,10]}$

Investigations on frontal WLs have been mostly made by mechanical characterization considering the influence of process parameters or filler content. An accepted rule of thumb states that with increasing melt or mold temperatures, the WL exhibits higher mechanical strength. ${ }^{[2,3,7]}$ A similar behavior has been observed with increasing packing pressure. ${ }^{[3]}$ With higher filler content, WLs have higher impact on the reduction of quasi-static tensile strength and failure strain. ${ }^{[4,6,13]}$ The strength of the WLs did not vary in parts with different thicknesses of PP composites. ${ }^{[14]}$

In terms of microstructure characterization at the frontal WLs, reflected light microscopy showed how fibers orient parallel to the frontal WL surface. ${ }^{[11]}$ By means of scanning electron microscopy (SEM) images, it has been shown a FO gradient with a width of at least 1 to $2 \mathrm{~mm}$ at frontal WLs. ${ }^{[5]}$ Using SEM and light transmission microscopy, it was demonstrated that the FO at the WL is dominant over the $\mathrm{V}$ notches on determining the frontal WL strength. ${ }^{[15]}$

Because of a good compromise between resolution and analyzed volume, X-Ray computed tomography (CT) has been widely used in the characterization of the microstructure of thermoplastics. Different characterizations of flowing WLs using CT are reported that is, in References ${ }^{[16-21]}$. A frontal WL was scanned with microfocus X-ray CT by Nagura et al. ${ }^{[22]}$ A quantitative analysis at four different $364 \times 364 \times 364 \mu \mathrm{m}^{3}$ zones showed that fibers at the WL orient in the transversal-to-flow direction and in the thickness direction. Lee et al. ${ }^{[23]}$ used micro-CT at a frontal WL and reconstructed the microstructure showing that the $\mathrm{FO}$ at the WL zone is mostly perpendicular to the flow direction.

Voids are also a factor of influence on the strength of injection-molded thermoplastic parts.

Recently, the use of CT scans to characterize voids has been widely spread as it enables an accurate determination of the void's size and content. ${ }^{[24-26]}$ Voids can form due to inhomogeneous thermo-mechanical shrinkage across the thickness, ${ }^{[27]}$ which takes place in injection-molded fiber- reinforced thermoplastics. The presence of voids has been also attributed to temperature, fiber content, and fiber length gradients that in turn lead to a different volumetric shrinkage behavior. ${ }^{[28]}$ Nevertheless, void formation at the WLs is less studied to the extent of the authors' knowledge. Voids were present at the frontal WL plane of 4 and $6 \mathrm{~mm}$ thick specimens, which were attributed to air entrapment. ${ }^{[15]}$ The formation of micro-voids at regions of transition of FO near the frontal WL were reported as a possible reason in weakening the WL region. However, the volume fraction of the microvoids was very small (less than $1 \%){ }^{[29]}$

Studies about the influence of the packing phase on the injection-molded parts show some ambiguities regarding its role on the FO. The influence of packing pressure is frequently correlated with the analysis of microstructure images or FO simulation results. A study suggests that during the packing phase, the FO at the core tends to orient more in the transverse direction. ${ }^{[30]}$ Using SEM images, an increase of thickness of the core layer has been noticed with higher packing pressure. ${ }^{[31]}$ On the other hand, using a theoretical model for long glass fibers, Tseng et al. ${ }^{[32]}$ found that the core thickness is reduced and the fibers become more oriented in flow direction during the packing phase.

For an economical and environmentally friendly part design, we need a reliable prediction of the mechanical properties at the WLs, which can be highly loaded regions of the part under service. Current integrative simulation chain approaches combine process and structural simulation to predict the mechanical behavior of a part. The phenomenon of molecular-diffusion at the WL interface has been modeled for unreinforced amorphous polymers by Kim and Suh. ${ }^{[9]}$ In the case of reinforced polymers, the prediction of the mechanical properties with WLs is however not reliable. ${ }^{[33]}$ WLs have actually proven to be a bottleneck in designing thermoplastic parts. In order to better predict the mechanical properties of WLs, a better understanding of the phenomena influencing their properties is required.

The FO behavior exactly at frontal WLs is well established, but mostly only based on 2D images. The state of the art lacks a quantitative characterization at the WL region. Studies in the literature are limited to small regions mainly at the WL plane. More importantly, the contribution of the several factors affecting the WL performance (polymer diffusion, fiber microstructure, voids, and V-notches) are not well studied. This work employs state of the art techniques to characterize the microstructure and correlate its influence on the shrinkage behavior at the WL, the formation of voids and the mechanical properties. Furthermore, the influence of the packing pressure and thickness on the microstructure of the WLs is studied. The influence of the factors weakening the WL is investigated to attain information on their relative contribution to the mechanical performance of frontal WLs in glass fiber-reinforced polybutylene-terephthalate (PBT). 
For this purpose, a specific mold was designed and two part thicknesses and two packing pressures were considered. Fiber volume fraction (VF), FO, and void content were determined quantitatively by X-ray $\mathrm{CT}$ at the frontal WL region. Surface topology scans were performed to understand the influence of FO changes on the thickness changes and shrinkage behavior at the WL. Tensile tests assisted by digital image correlation (DIC) were done to correlate the mechanical response with the quantified process-induced microstructure at the WLs.

\section{2 | EXPERIMENTAL}

\section{1 | Sample preparation}

A PBT reinforced with $30 \mathrm{wt} \%$ glass fibers was used (average $\mathrm{VF}=0.18$, mean fiber length $=200 \mu \mathrm{m}$, and fiber diameter $=10 \mu \mathrm{m})$. The injection-molded specimen is described in Figure 1. A width of $15 \mathrm{~mm}$ larger than the one of standard ISO 527 tensile sample was chosen to limit the influence of sidewalls (lateral walls). The mold was provided with ventilation channels at the WL zone $(10 \mathrm{~mm}$ width and $0.01 \mathrm{~mm}$ depth) to limit the appearance of $\mathrm{V}$-notches and voids induced by air entrapment. Specimens with two thicknesses (1.5 and 3.0) $\mathrm{mm}$ were produced using an injection-molding machine DK-Codim 175/410. The following process parameters were fixed: Injection time $\sim 2.3 \mathrm{~s}$, mold temperature of $60^{\circ} \mathrm{C}$, melt temperature of $250^{\circ} \mathrm{C}$, and holding time of $5 \mathrm{~s}$. The holding pressure was varied in two levels: 40 and $60 \mathrm{MPa}$.

\section{2 | Mechanical testing}

Quasi-static tensile tests were made using an Instron 5966 machine. The strain was measured with an optical extensometer with an initial reference length between 10 and $12 \mathrm{~mm}$. Clamp speed was fixed at $10 \mathrm{~mm} / \mathrm{min}$. Further evaluations of the strain field were made with a DIC system Q-400 from LIMESS and the software ISTRA4D (4.4.4) from Dantec Dynamics. The DIC evaluations were made on the same specimens of the ones scanned with CT analysis.

\section{3 | X-ray computed tomography}

Injection molded specimens were scanned directly without machining them. Positions of the scanned regions are shown in Figure 1. Scans were made using a CT system GE vltomel x m 300/180 Metrology Edition with a Nanofocus X-ray tube and the following parameters: Mode $1, \mathrm{X}$-ray tube voltage $100 \mathrm{kV}, \mathrm{X}$-ray tube current $135 \mu \mathrm{A}$, exposure time per projection $500 \mathrm{~ms}, 3300$ projections, no prefiltration and a voxel size of $2.9 \mu \mathrm{m}$. The system used a $16 \mathrm{MPixel}$ detector dynamic 41/100 without any binning. A first series of CT scans were carried out on the specimens injection molded with a packing pressure of $40 \mathrm{MPa}$ (PP40). Each scan zone had a size of $5 \times 10 \times 1.5$ or $5 \times 10 \times 1.5 \mathrm{~mm}^{3}$ and was transversal to the WL. The scans were merged together into a single microstructure to obtain the FO and VF results on a $10 \times 10 \times t \mathrm{~mm}^{3}$ zone. A second series of CT scans $\left(10 \times 10 \times 3 \mathrm{~mm}^{3}\right)$ was done on a $3 \mathrm{~mm}$ specimen injection molded with a packing pressure of $60 \mathrm{MPa}$ (PP60).

\section{4 | Determination of fiber orientation, fiber volume fraction, and void content}

The software VG Studio Max 3.1 from the company Volume Graphics was used to reconstruct the CT images. The evaluation of FO and VF was based on a local filtering method, which uses gradient threshold values and computes a local FO for each voxel without performing a segmentation of single fibers. The computed voxel values of FO and VF were averaged on the elements of a regular hexahedral mesh with an element size of $0.2 \mathrm{~mm}$. For each mesh element, VG Studio Max 3.1 computes a second-order FO tensor as defined by Advani and Tucker. ${ }^{[34]}$

Figure 2 shows an example of the obtained FO results on the hexahedral mesh. In each main direction, the mesh can be divided into layers. In the following, the FO results are presented by averaging the values of each layer according to the direction of analysis. The SD of the mean value of the component of the second-order FO tensor depended on the number of layers under consideration. The maximal obtained value was $\sim 0.035$ for a single evaluation point. Due to the low value of deviation, it will not be plotted in the figures.
FIGURE 1 Specimen dimension and the computed tomography scan regions $(10 \mathrm{~mm}$ scanned of $15 \mathrm{~mm}$ complete width). The red marked region is for the $1.5 \mathrm{~mm}$ weld line (WL; symmetric). The blue marked region represents the $3 \mathrm{~mm}$ WL with two packing pressures $(40,60)$ $\mathrm{MPa}$ (scanned asymmetrically to include a larger region)

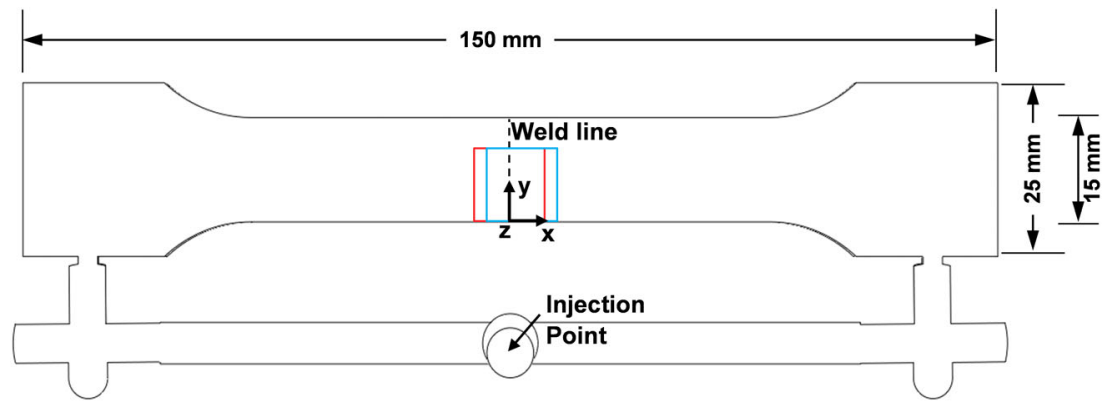


(A)

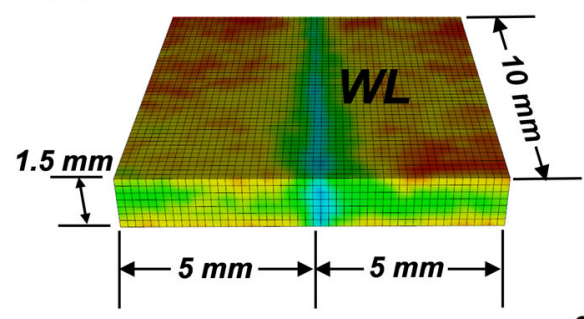

(B)

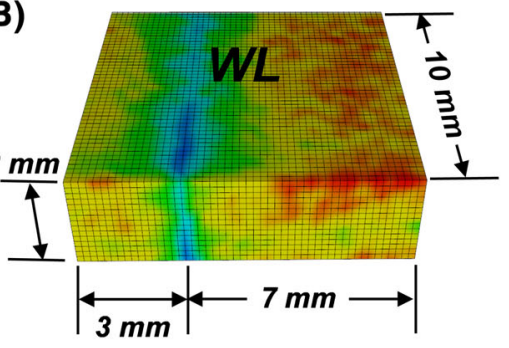

FIGURE 2 Visualization of the fiber orientation evaluation in samples with two thicknesses: A,

$1.5 \mathrm{~mm}$; B, $3 \mathrm{~mm}$
The mesh was placed so that the three main FO tensor components are in the directions of the Cartesian coordinates shown in Figure 1. This means that the $a_{11}$ component corresponds to the FO in $x$ direction (flow direction), $a_{22}$ is the FO in $y$ direction (transversal to flow) and $a_{33}$ is the FO in $z$ direction (thickness direction). These three directions are very close to the main principle directions given the very low values of the measured off-diagonal tensor components $\left(a_{12}, a_{23}, a_{13}\right)$.

Quantitative analysis of the void content were performed by applying a median filtering to eliminate the noise inside the voids followed by a surface determination to define the void boundaries. Micro voids smaller than 36 voxels (ie, $900 \mu \mathrm{m}^{3}$ ) were neglected due to software limitations in the quantitative analysis of voids.

\section{5 | Surface profilometry measurement}

Surface topology measurements were made with a Veeco Dektak 150 Profilometer $(12.5 \mu \mathrm{m}$ radius stylus, resolution $2.4 \mu \mathrm{m}$ ) assisted with the software Vision (4.2). The preset measuring-profile used was "Hills\&Valleys" with a stylus force of $3 \mathrm{mg}$. The reference plane is chosen as the one with the most probable height level, which was coincident with the specimen surface away from the WL.

\section{3 | RESULTS AND DISCUSSION}

\section{1 | Mechanical properties of frontal weld lines}

Rheological tests have shown that the longest relaxation time of the used PBT matrix is approximately $4 \mathrm{~ms}$ at the selected injection temperature. ${ }^{[5,21]}$ For the processing times used in this work, then a complete matrix healing at the WL surface is expected. Tensile tests on the unreinforced PBT specimens proved the complete matrix healing at the WL given the fact that the specimens with and without WL did not exhibit different tensile stress/strain at yield (Figure 3). Failure of the specimens with WL of the unreinforced

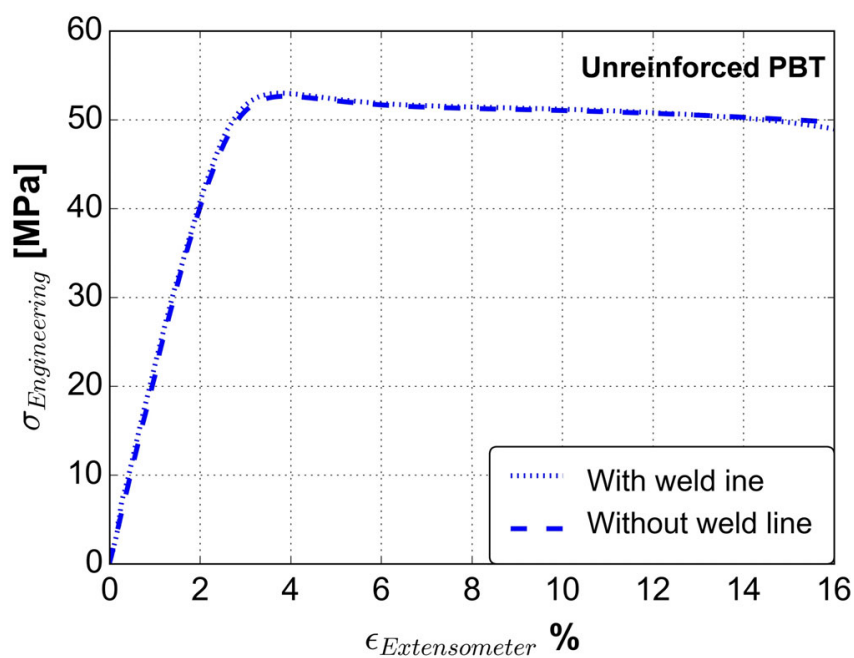

F I G U RE 3 Tensile stress-strain diagram of two specimens with and without WL of unreinforced PBT. Failure in both samples took place at the specimen's shoulder. PBT, polybutylene-terephthalate; WL, weld line

variant took place at the shoulder of the specimen and not at the WL.

Tensile testing results in Figure 4 of the fiber-reinforced PBT show the severity of frontal WLs (five specimens for each case). The failure always took place exactly at the WL and the strength reduction factor reached about 0.55 . The tensile strength at break of the $1.5 \mathrm{~mm}$-thick sample with $\mathrm{WL}$ is $7 \%$ higher than the one of $3 \mathrm{~mm}$ (Figure $4 \mathrm{~A}$ ). Failure strain is reduced by $35 \%$ and $45 \%$ for the 3.0 and $1.5 \mathrm{~mm}$ samples with WL, respectively. The $1.5 \mathrm{~mm}$-thick WL have a higher strength, however, a lower failure strain than the $3.0 \mathrm{~mm}$-thick sample. This can be attributed to the thinner core layer of the $1.5 \mathrm{~mm}$ specimen. In injection-molded thermoplastics, a skin-core microstructure is present with fibers oriented in flow direction at the skin (shell) layers and transversally to the flow at the core layer and the thickness of the core layer increases with increasing thickness. ${ }^{[35]}$

The influence of the packing pressure on the WL strength was found to be significant (T-Student at 95\% of confidence). In fact, the average failure strength of the specimens 
FIGURE 4 A, Average

failure stress; B, average failure strain of $30 \mathrm{wt} \%$ glass fiber PBT specimen with and without WLs. Error bar length is the SD of five tests. PBT, polybutyleneterephthalate; WL, weld line
(A)

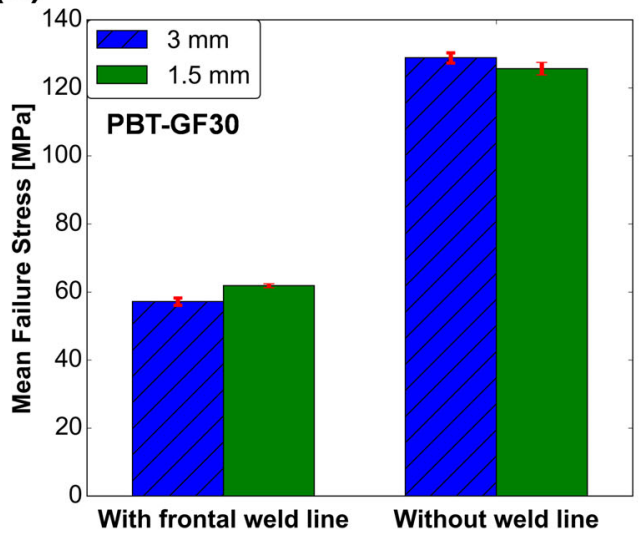

(B)

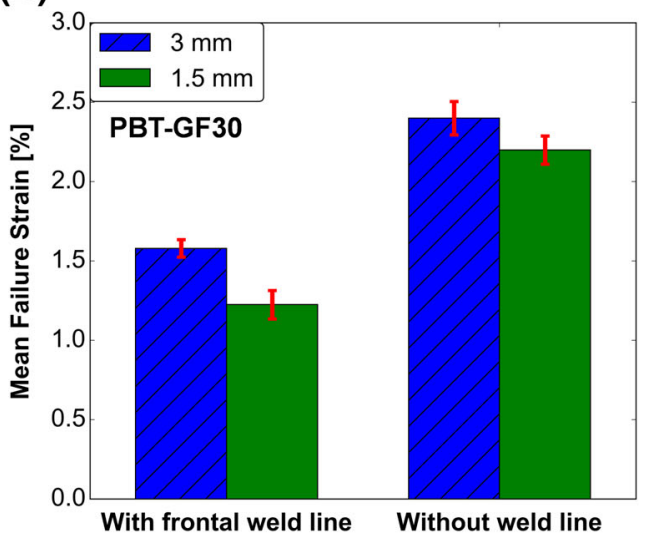

with $60 \mathrm{MPa}$ increased by around $3 \mathrm{MPa}$ with respect to the one of the specimens with $40 \mathrm{MPa}$. The increase of strength of the WLs with increasing packing pressure has also been reported by Kagitci and Tarakcioglu. ${ }^{[36]}$

The fact that the used matrix in this work exhibits a very high healing ability at welding eliminates the role of the lack of matrix healing (interdiffusion) on weakening the WL. The mold and melt temperatures played no role in increasing the strength of the $\mathrm{WL}^{[5]}$ that further confirms the good welding ability of the PBT polymer matrix under injection-molding conditions. The failure strength at the WL was 3 to $7 \mathrm{MPa}$ higher than the maximum strength of the unreinforced matrix, which indicates that composite failure was reached after matrix failure.

\section{2 | Fiber orientation}

Figure 5A plots the FO along the flow direction of the $3 \mathrm{~mm}$ WL (PP40 case, average value taken across the width and thickness). The region near to the specimen side surface ( $2 \mathrm{~mm}$ ) was not considered to eliminate the lateral wall effects. Large variations of $a_{11}$ and $a_{22}$ appear $2 \mathrm{~mm}$ before the WL plane, which means that the induced FO microstructure at the WL is at least $4 \mathrm{~mm}$ wide. In fact, fibers start to orient more in thickness and transverse direction by nearing the WL plane. In the WL plane, most of the fibers are oriented in the transverse direction $\left(a_{22}\right.$ component reaches a maximum value of about 0.75 ). This wide FO gradient in the flow direction $\left(\frac{\Delta a_{11}}{\Delta x}\right)$ could be explained by the extent of the fountain flow front. As the flow stops at the frontal WL, the remaining FO microstructure at the frontal WL is characteristic of the FO induced by the fountain flow.

For the $3.0 \mathrm{~mm}$-thick specimen with WL, the highest orientations in thickness direction are not found at the WL plane, but at regions beside the WL plane that are located $\sim 2 \mathrm{~mm}$ away from the WL plane (see Figure 5A).

The FO along the WL, that is, in the transversal-to-flow direction, can be visualized in Figure 5B. The fibers are preferentially oriented in the flow direction at the specimen's sidewall, but their orientation evolves over a distance of around $1.5 \mathrm{~mm}$. From this position, fibers orient mainly parallel to the WL surface and remain with this global orientation.

The high orientation in flow direction at the sidewall could be explained by the influence of the shear rate profile near the wall, which orients the fibers in flow direction. The increase of FO in thickness direction at the sidewall will be discussed later in this work.

Figure 5C compares the $\mathrm{FO}$ results in thickness direction at the $\mathrm{WL}$ region. The highest $\mathrm{FO}$ in thickness direction takes place at the core. In fact, at the core region, the fibers orient only in thickness and transverse to flow direction. This behavior depicts the typical fountain flow behavior associated with injection molding. This means that nearly no fibers are oriented in the flow direction. As consequence, when loading this frontal WL in flow direction the fibers will practically not reinforce the parts.

\section{3 | Influence of thickness on the fiber orientation at the weld line}

Figure 6A compares the FO at the WL between the two studied thicknesses: 1.5 and $3 \mathrm{~mm}$. The results are presented in flow direction, it means that results have been averaged over the thickness and the width of the specimen $(2 \mathrm{~mm}$ at the sidewall were not considered to exclude the particular microstructure observed in Figure 5B). On one hand, the FO gradient in flow direction at the WL in the $1.5 \mathrm{~mm}$ specimens is smaller than the one in $3 \mathrm{~mm}$ specimens. On the other hand, the change of FO along the flow direction in the $1.5 \mathrm{~mm}$ specimen is less abrupt. The FO in the $1.5-\mathrm{mm}$ thick specimen is less oriented at the WL region. In fact, in the $1.5 \mathrm{~mm}$ case, the fibers are oriented more in thickness direction and less in transverse direction compared to the $3.0-\mathrm{mm}$ thick specimen. The increase of the fibers oriented in flow direction can be explained by the higher shear rates in flow direction found in thinner parts, which would tend to orient 
(A)
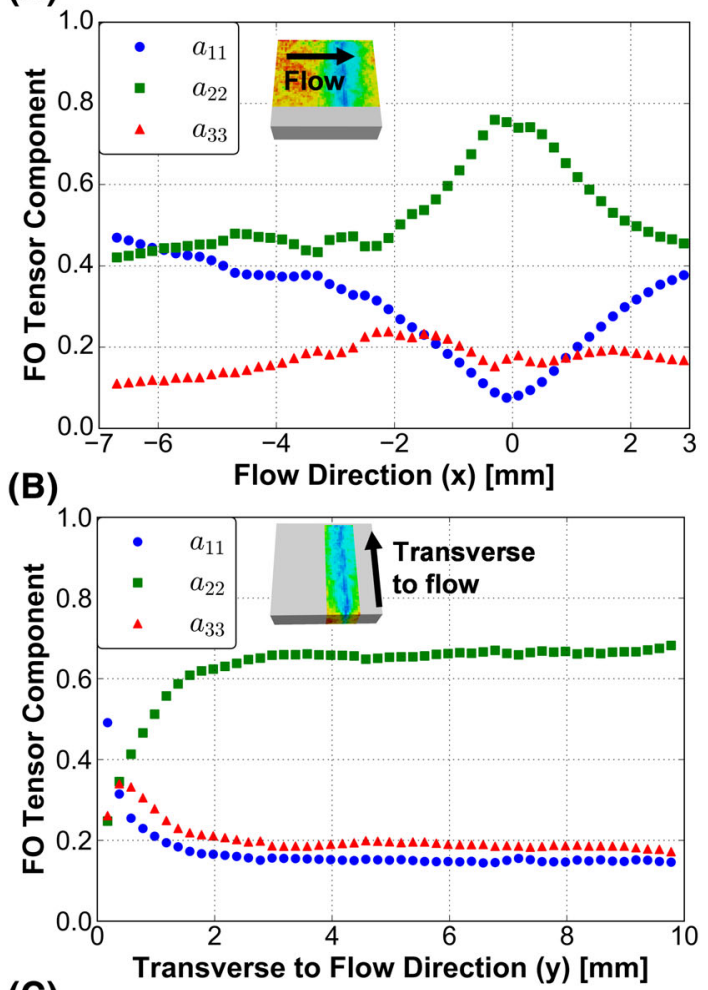

(C)

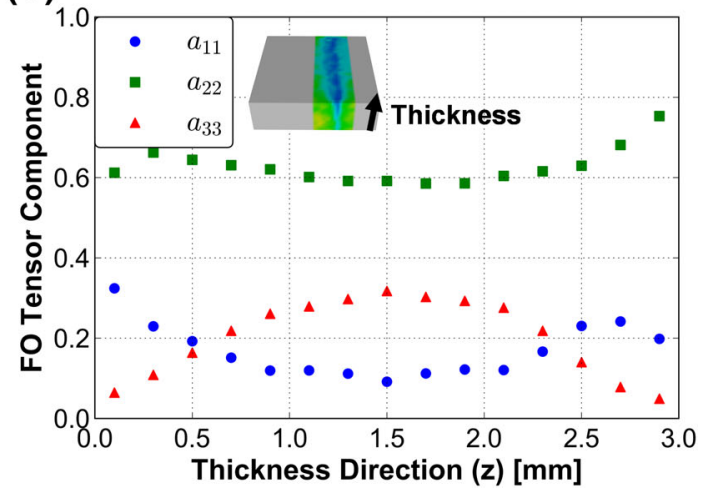

F I G URE 5 FO at the WL of a $3.0 \mathrm{~mm}$ sample (packing pressure $40 \mathrm{MPa}$ ) evaluated at the colored regions of the represented specimens. A, In flow direction $(x)$ averaged over thickness and width (WL at $0 \mathrm{~mm}$ ); B, parallel to WL ( $y$-direction) averaged over thickness and $3 \mathrm{~mm}$ width (complete specimen width $15 \mathrm{~mm}$ ); $\mathrm{C}$, in thickness direction $(z)$ averaged in $x$ - and $y$ - directions. FO, fiber orientation; WL, weld line

more fibers parallel to the flow direction. This increase of fibers oriented in flow direction explains the increase of mechanical strength of the WL in $1.5 \mathrm{~mm}$ specimen as shown in Figure 4.

To understand the difference in $\mathrm{FO}$ between the two thicknesses, Figure 6B plots the FO over the normalized thickness averaged at the WL region, that is, volume found at distances lower than $1.5 \mathrm{~mm}$ from the WL plane. In the thinner part, the FO is less oriented and in average nearly isotropic in space. In both thicknesses, however, the FO in the thickness direction increases from the skin to the core layer.

The higher FO in thickness direction exactly at the WL plane in the thinner part compared to the thicker part can be supported by the wider WL region at the $3 \mathrm{~mm}$ part as shown in Figure 7.

The images were taken from the CT-scans at a section $4 \mathrm{~mm}$ away from the sidewall $(y=4 \mathrm{~mm})$. When considering the core region, the width of the WL can be qualitatively measured from the fibers oriented preferentially in thickness direction. The WL region of the $3.0 \mathrm{~mm}$ specimen is around $2 \mathrm{~mm}$ wide and the fibers oriented in thickness direction lay mainly besides the WL plane (dashed lines in Figure 7B). In the $1.5 \mathrm{~mm}$ part, the width of the WL is $\sim 0.5 \mathrm{~mm}$ with fibers oriented in thickness direction exactly at the WL. This induced microstructure in both thicknesses was also observed in other specimens examined under SEM.

The difference of the FO with changing thickness could be related with the development of the flow front profile along the flow. The development of the fountain flow at the flow front has been simulated elsewhere. ${ }^{[37]}$ Higher velocities develop faster the fountain flow and in turn orient faster the fibers in the thickness direction at the flow front. However, this hypothesis could be rejected by considering the flow distance until the WL location $(50 \mathrm{~mm})$, which could be sufficient for developing completely the fountain flow in both thickness. A further explanation could be based on the fact that the thickness of the solidified layer at the wall (or regions with high viscosity due to cooling) is the same for the two specimens in absolute value, but not relatively to the cavity thickness. This would induce a change of velocity gradient across the thickness, which could be responsible for the observed differences of FO at the WL zone.

CT-scans on short shots at the flow front or mechanistic direct fiber simulation could help better understand the influence of the thickness on the development of the FO at the flow front and provide more robust explanations of the microstructure in Figure 7.

In addition, the flow-induced FO at the WL is more distorted by the packing pressure phase in the $3 \mathrm{~mm}$ case than in the 1.5 one. ${ }^{[5]}$ The influence of the packing pressure is more important in the $3 \mathrm{~mm}$ case because of the slower solidification in comparison with the $1.5 \mathrm{~mm}$ specimens. The influence of the packing pressure will be discussed more in detail later on.

\section{4 | Shrinkage behavior at the weld line: Influence of fiber orientation}

A surface topology scan at one side of the WL is presented in Figure 8. The reference plane is the specimen surface 
(A)

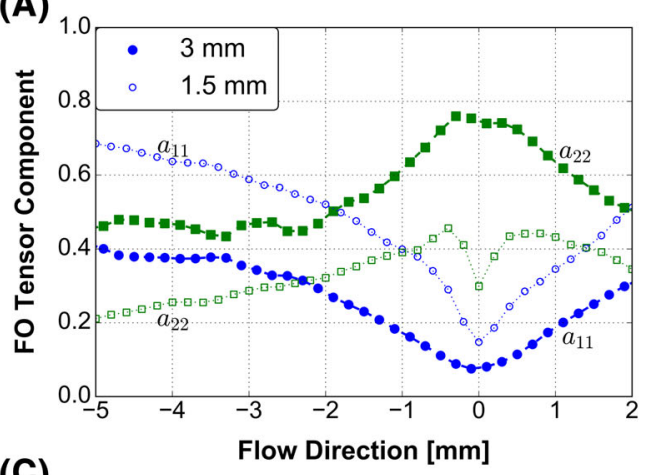

(C)

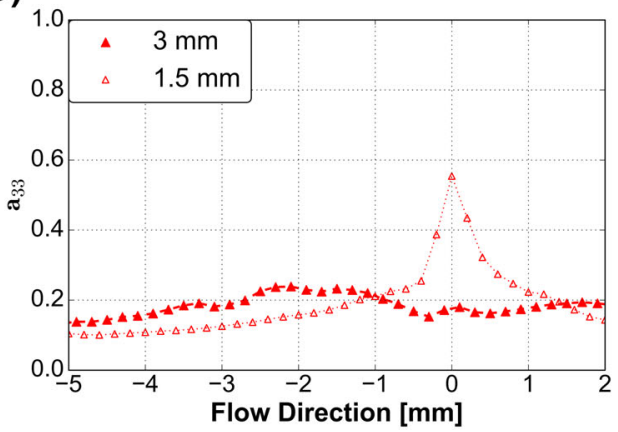

(B)

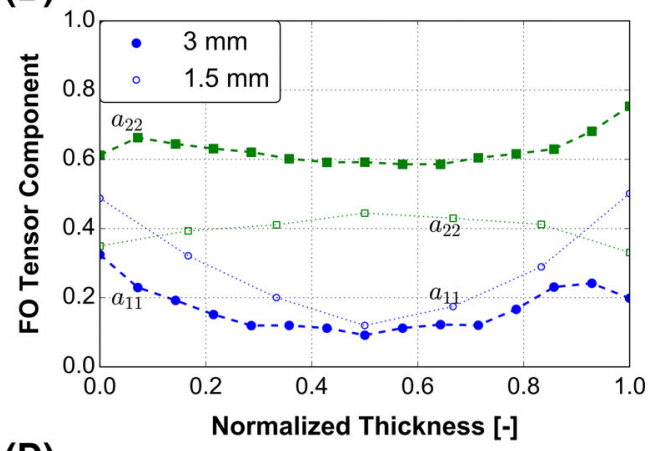

(D)

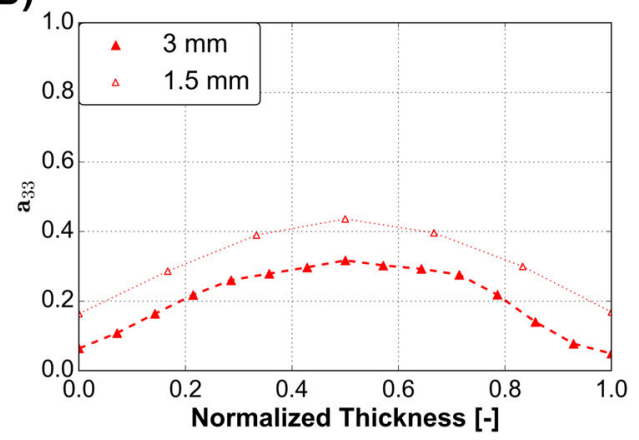

F I G U RE 6 Comparison of the FO between 1.5 and 3.0 mm-thick WLs. A, In flow direction (WL plane located at 0 mm), averaged over width and thickness. B, In thickness direction averaged over flow and transverse directions at the WL. FO, fiber orientation; WL, weld line
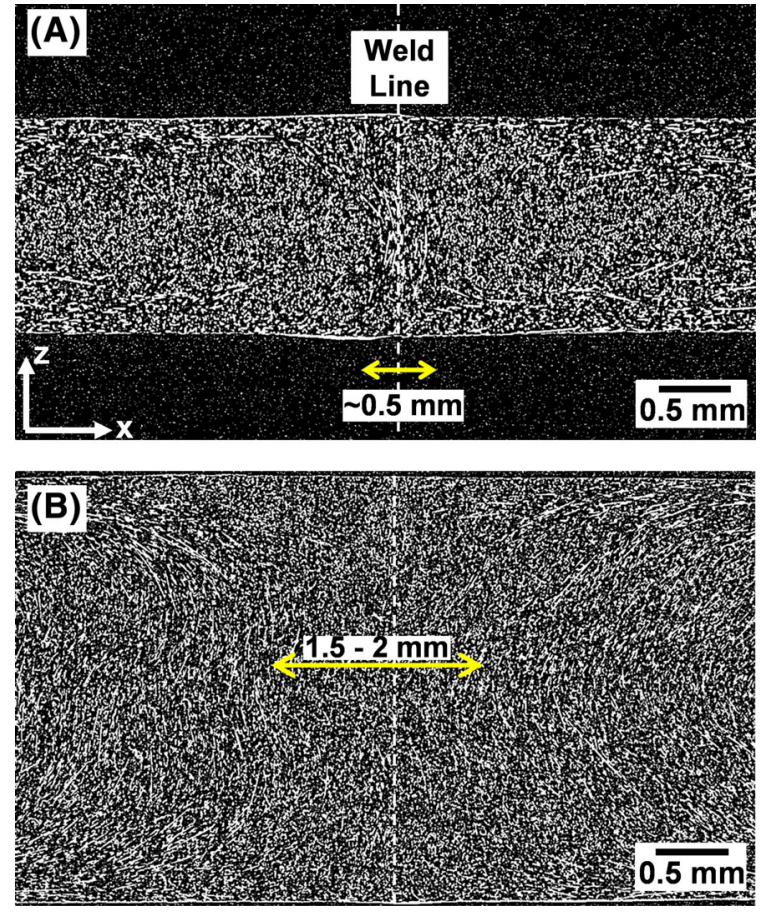

F I G URE 7 Images from CT scan of sections in flow direction $(y=4 \mathrm{~mm}$ ) across the WL (dashed lines) for two different specimen thicknesses: A, $1.5 \mathrm{~mm}$; B, $3.0 \mathrm{~mm}$. CT, computed tomography; WL, weld line

away from the WL. Results show an increase of thickness up to $30 \mu \mathrm{m}$ in the $1.5 \mathrm{~mm}$ WL and $15 \mu \mathrm{m}$ in the $3 \mathrm{~mm}$
(A)
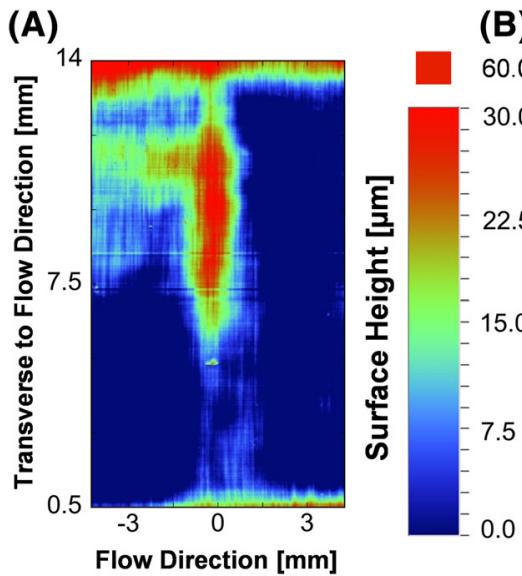

(B)

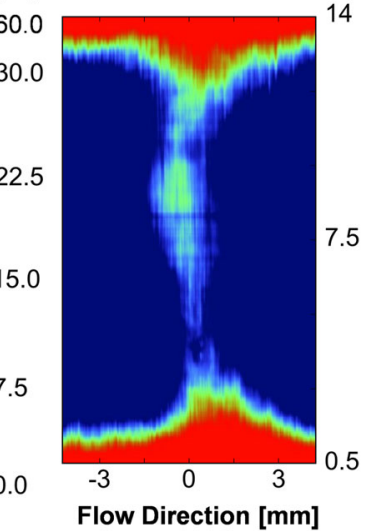

F I G U R E 8 Topology scans of frontal weld lines of different thicknesses: A, $1.5 \mathrm{~mm}$; B, $3.0 \mathrm{~mm}$ (packing pressure of $40 \mathrm{MPa}$ )

WL. This result excludes the formation of a V-notch at the WL. This increase in thickness is related to the increase of FO in thickness direction at the WL shown in Figure 5C, which is related to the fountain flow behavior.

In fact, as the flow stops at the frontal WL also the development of FO ceases and the final FO at the frontal WL is associated to the microstructure induced by the fountain region, which orients the fibers perpendicular to the flow direction (ie, in transversal and thickness direction). As consequence, the fibers that remain oriented in thickness direction limit the shrinkage at the WL region compared to the 
regions away from the WL. This increase in thickness can be observed in Figure 7.

An increase of the thickness-averaged FO component in thickness direction $\left(a_{33}\right)$ from $\sim 0.2$ in the $3 \mathrm{~mm}$ case to $\sim 0.35$ in the $1.5 \mathrm{~mm}$ case, led to an increase of the surface height from 15 to $30 \mu \mathrm{m}$. This suggests a relation between the shrinkage-driven surface height at the WLs and the FO in thickness direction.

To support the correlation between FO and shrinkage behavior, anisotropic FE simulations were made using a thermoelastic matrix material law and a Mori Tanaka homogenization scheme. ${ }^{[38]}$ For this calculation, an averaged FO tensor over the thickness at the WL plane was employed. For the Eglass fibers, an elastic modulus of $72 \mathrm{GPa}$, a Poisson's ratio of $0.22^{[39]}$ and an aspect ratio of 25 were supposed. For the polymer matrix, an elastic modulus of $2230 \mathrm{MPa}$ and a Poisson's ratio of 0.4 were used, which were identified from tensile test experiments carried out on the respective unreinforced PBT. Coefficients of thermal expansion at different temperatures were measured for the PBT-matrix using a TMA analysis between $-20^{\circ} \mathrm{C}$ and $175^{\circ} \mathrm{C}$. The values ranged between $\sim 7 \times 10^{-5}$ and $\sim 1.5 \times 10^{-4}$.

A thermal simulation on a cube was performed by cooling from melt temperature $\left(250^{\circ} \mathrm{C}\right)$ to mold temperature $\left(60^{\circ} \mathrm{C}\right)$. Results show a clear difference in the shrinkage with the different FO tensors. The $1.5 \mathrm{~mm}$ case $\left(a_{11}=0.25\right.$, $a_{22}=0.4$, and $a_{33}=0.35$ ) has led to nearly half the displacement in $z$ direction compared to the $3 \mathrm{~mm}$ one $\left(a_{11}=0.17\right.$, $a_{22}=0.63$, and $a_{33}=0.2$ ). These results support the correlation between FO and shrinkage behavior in the thickness direction at the WL. A correlation between the FO and the shrinkage of a thin walled part in general was also suggested in Reference ${ }^{[40]}$.

At the sidewalls of the specimens, an increase in surface height of nearly $65 \mu \mathrm{m}$ is also clear. This behavior can also be explained by the induced FO at the walls. Figure 5B shows the increase of the $\mathrm{FO}$ in thickness direction at the sides of the specimen (from $y=0 \mathrm{~mm}$ to $y=0.6 \mathrm{~mm}$ ). The increase of FO at the walls should be induced by the complex velocity gradient associated with a three walls confinement. The slower velocities of the flow front at the sidewalls compared to the center of the specimen might also play a role.

The increase of thickness at the walls was nearly two times higher than at the WL, however, FO tensor component in thickness direction was similar and close to 0.35 . This could be related to a constrained shrinkage at the sidewall in comparison with regions in the middle of the sample. In both cases, however, the FO in thickness direction at the WL reduces the shrinkage potential of the polymer matrix and hinders the apparition of V-notches at the WL.

\subsection{Influence of packing pressure}

The influence of packing pressure was studied by comparing the $\mathrm{FO}$ of the $3 \mathrm{~mm}$ specimens injected with packing pressure of $40 \mathrm{MPa}$ (PP40) and $60 \mathrm{MPa}$ (PP60). Figure 9A shows a comparison of the FO in flow direction by averaging the orientation tensors in width and thickness directions of the scan. At normal distances higher than $\sim 3 \mathrm{~mm}$ from the WL plane (at $x=0$ ), the change in packing pressure has a low impact on the induced FO and both cases exhibit a similar behavior. However, at the WL plane, a distortion of FO by increasing the packing pressure is noticed. The higher packing pressure (PP60) led to a reduction of the FO gradient $\left(\frac{\Delta a_{22}}{\Delta x}\right)$ at the WL with less fibers oriented in the transversal to flow direction.

Figure 9B compares the FO at the WL through the thickness by averaging the orientation tensors between $x=$ $-1.5 \mathrm{~mm}$ and $x=1.5 \mathrm{~mm}$. At the core layer, one observes the larger differences of induced FO. With the higher packing pressure, the fibers orient more in flow direction. The

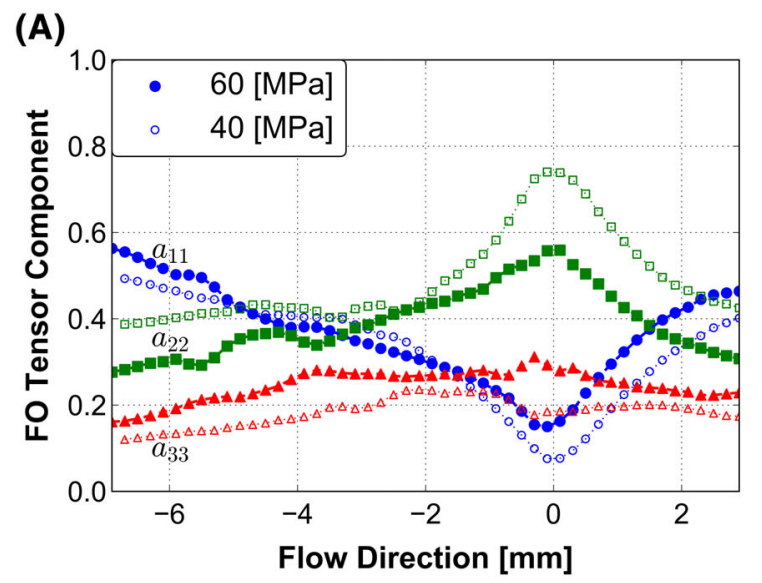

(B)

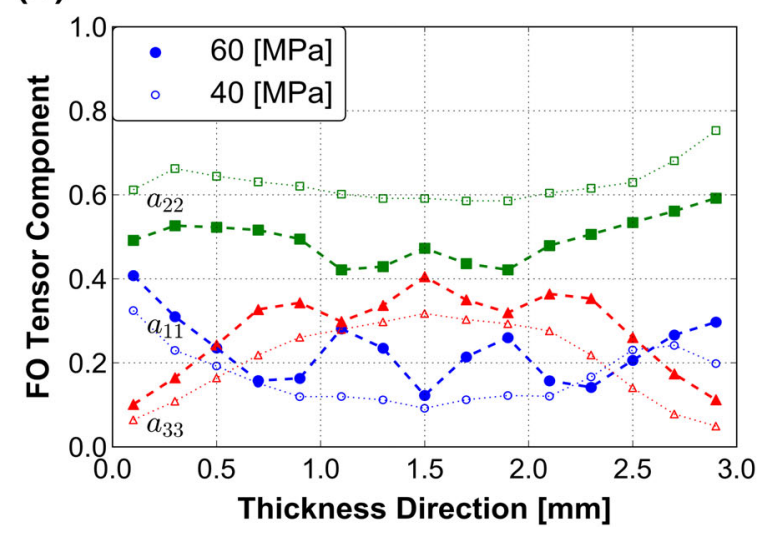

FI G URE 9 Comparison of the FO between the two packing pressures (40 and $60 \mathrm{MPa}$ ) in $3 \mathrm{~mm}$-thick specimens. A, In transverse to flow direction (WL at $0 \mathrm{~mm}$ ) averaged over width and thickness. B, In thickness direction averaged of $3 \mathrm{~mm}$ width at the WL. FO, fiber orientation; WL, weld line 
small increase of FO in flow direction and the respective smoothing of the FO gradient explain the slight increase in tensile strength with higher packing pressure (section 3.1). In fact, those specimens exhibited a tensile strength difference of $\sim 4.5 \mathrm{MPa}$

Figure 10 presents comparison of the $\mathrm{FO}$ results at the core layer (from $z=0.8 \mathrm{~mm}$ to $z=1.4 \mathrm{~mm}$ ) between the two packing pressures. The FO shows clear changes with the higher packing pressure at the core layer. The FO gradient exactly at the WL is nearly eliminated. On the contrary, the FO at the skin layers was very similar between both specimens.

Due to a probable nonsymmetric thickness of solid layers on each side of the WL, the flow during the postfilling can explain this reorientation of the fibers at core. In fact, the flow at core induced by the higher packing pressure would tend to reorient the fibers also in flow direction at the boundary between the solidified polymer layers and the molten core. This would explain the two peaks of $a_{11}$ at the core of the PP60 specimen in Figure 9B. In addition, the flow during packing would also deform the WL plane leading to a smoothing of the FO gradient at core. The previous results agree with the findings in Reference ${ }^{[31]}$, where the authors explain that during the postfilling stage, the viscosity in the core region is lower than the one in the shell layers leading to a higher orientation in flow direction.

\subsection{Fiber volume fraction}

Fiber VF analysis shows a sharp decrease at the WL plane for the $1.5 \mathrm{~mm}$ sample and a smoother reduction around the WL region for the $3 \mathrm{~mm}$ one (Figure 11). In both cases, a decrease in VF of around 0.010 to 0.012 is observed, which means a reduction of weight fraction of about $2 \%$ to $3 \%$. The variation of packing pressure on the $3 \mathrm{~mm}$ specimens did not bring differences in the VF distribution. The reduction of

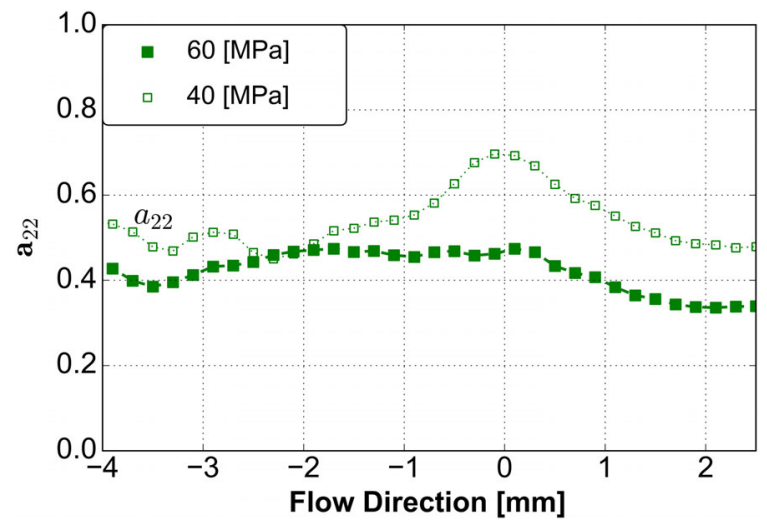

F I G URE 10 Comparison of the FO at the 3.0 mm-thick WL between two packing pressures (40 and $60 \mathrm{MPa}$ ) at the core layer $(0.8 \mathrm{~mm}<z<1.4 \mathrm{~mm})$. FO, fiber orientation; WL, weld line

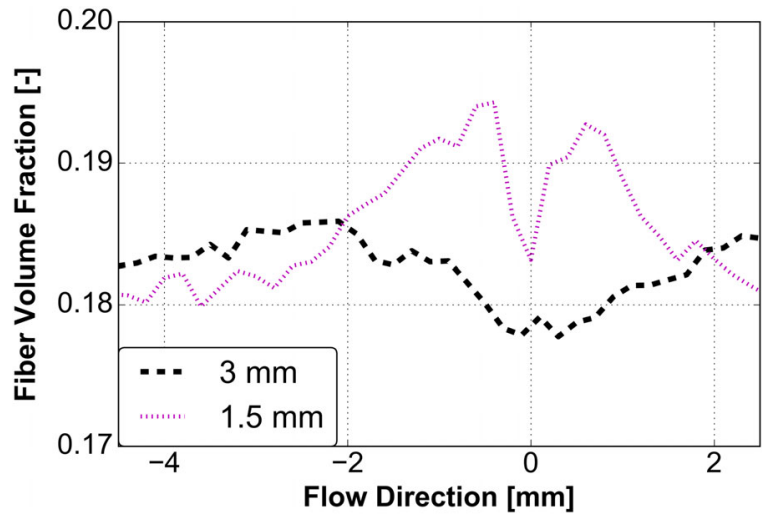

F I G URE 11 Evaluation of the fiber volume fraction along flow direction $(x ; \mathrm{WL}$ is at $x=0)$ and averaged over the thickness and width of the CT-scan sample. The evaluation of fiber volume fraction was performed in VG Studio Max 3.1. CT, computed tomography; WL, weld line

VF in the vicinity of the WL plane of the $1.5 \mathrm{~mm}$ sample can also be visualized in Figure 7A.

In general, the measured decrease of VF can be explained by the fiber migration induced by the higher deformation rate encountered at the flow front. In fact, particle migration is triggered by shear rate gradients ${ }^{[11,42]}$ and the characteristic elongational deformation of fountain flow ${ }^{[43]}$ would then promote the fibers to move away from the flow front. This phenomenon has been simulated by Kurth et al. with a mechanistic model to predict the movement of short fibers near the flow front. ${ }^{[44]}$ It was explained that due to fiberfiber interactions fibers could not reach the flow front. The collision of the two flow fronts at the frontal WL would then induce a reduction of the fiber $\mathrm{VF}$ in a region around the WL, whose extend depends on the profile of the developed flow front.

The impact of the observed variations in VF on the mechanical performance at the WL is expected however to be low. In fact, by varying the VF in the range measured for this material, we estimated a change of up to $4.0 \%$ on the Young's modulus in the three principal directions using the Mori Tanaka micromechanical model and the material parameters mentioned before in section 3.4. This variation of Young's modulus should not have a significant impact on the WL strength.

\section{7 | Void content}

Figure 12 allows to identify voids at the cutting plane $z=1.5 \mathrm{~mm}$ in the vicinity of the frontal WL of the $3 \mathrm{~mm}$ specimen injected with a packing pressure of $40 \mathrm{MPa}$. The mentioned cutting plane, which extends from one sidewall up to $6 \mathrm{~mm}$ in the $y$-direction, is sketched in Figure 12A. At the skin and shell layers, no voids were detected. In fact, 
(A)
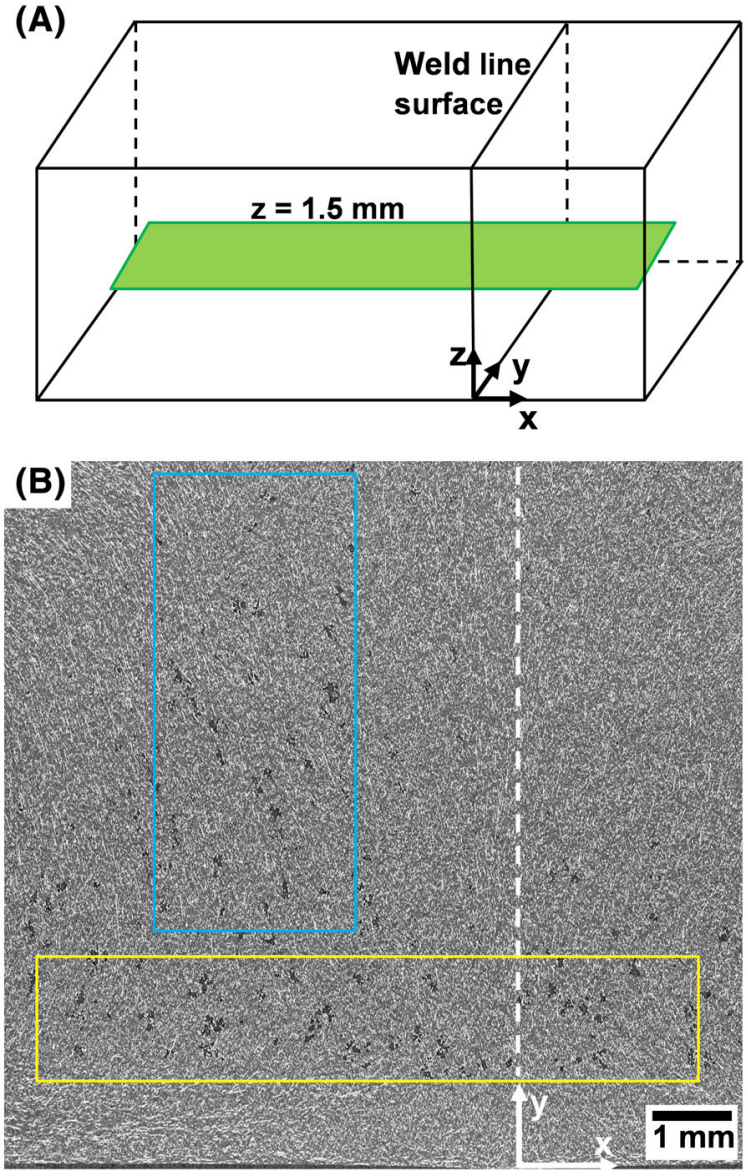

F I G URE 12 A, Sketch of the plane $(z=1.5 \mathrm{~mm})$ used for analyzing the voids content on a $3.0 \mathrm{~mm}$-thick specimen. B, computed tomography-image of the analysis plane of a specimen injected with $40 \mathrm{MPa}$ packing pressure

only at $\sim 0.9 \mathrm{~mm}$ from the specimen surface, voids started to be visible. Interestingly, nearly no voids were observed at the WL. The size and quantity of voids increased across the thickness and reached a maximum at the core as shown in Figure 12B. It is possible to identify two regions of high concentration of voids. One region near to the wall side of the mold (marked in yellow) and another region located at $\sim 3 \mathrm{~mm}$ before the WL plane (marked in blue). The location of the voids in the region near the wall (marked in yellow) lays at the same $y$-position, where the FO gradient in transverse to flow direction exhibits an abrupt change, as shown in Figure 5B.

The voids in the central region (marked in blue) correlate similarly to the induced FO in Figure 5A, where voids locate at the region where fibers exhibit a steeped change in fiber orientation.

The specimen injected with packing pressure of $60 \mathrm{MPa}$ showed a similar voids distribution as described for the PP40 sample. However, the void size (void VF) is reduced with higher packing pressures. In fact, based on a quantitative 3D analysis performed at the core layers of the PP40 and PP60 samples showed a reduction of voids content from 0.41 to $0.163 \mathrm{~mm}^{3}$ by enhancing the packing pressure from 40 to $60 \mathrm{MPa}$.

In the $1.5 \mathrm{~mm}$ case, a lower voids content was observed, but with an analogue spatial distribution. The voids are found from $z=\sim 0.65 \mathrm{~mm}$ to $z=\sim 0.85 \mathrm{~mm}$. The void content reaches a maximum at $z=\sim 0.75 \mathrm{~mm}$, which is the mid plane of the thickness. A high concentration of voids was also visible before the WL plane $(\sim 1 \mathrm{~mm}$ from it) and near the sidewall of the cavity. Similar to the case of $3 \mathrm{~mm}$, the voids are concentrated within regions where a steeped change in FO gradient takes place. For example, the voids that form in the planes $y \sim \pm 1 \mathrm{~mm}$ (coplanar to the WL plane) are located in a region before where the FO in thickness direction changes abruptly (Figure 6A).

The previous results suggest a strong correlation between the FO and void formation. Regions that solidify later in the injection process, that is, core zones, are prone to void formation by anisotropic shrinkage potential. Voids form before the WL-plane and close to the sidewalls. These two regions show steeped changes of FO gradient. This change of FO would influence the local shrinkage behavior. Higher packing pressures can however reduce the void content due, from one hand, to the higher core densification and, from the other one, to the smoothing of the induced FO gradient.

The concentration of the voids was found at least 1 to $3 \mathrm{~mm}$ besides the WL plane. Tensile tests on all specimens with WL failed exactly at the WL plane. This could point out a low influence of the voids on the WL strength. However, the voids could affect the stress distribution at the WL region and, in consequence, the transferred load to the WL plane. Thus, we lack of information for providing a definitive statement concerning the impact of voids on the quasistatic tensile properties of frontal WLs.

In this specific case, no voids were formed due to air entrapment at the WL surface, suggesting the positive influence of ventilation channels and a suitable choice of process parameters. A further CT-scan made on a $3 \mathrm{~mm}$ frontal WL specimen injected with a packing pressure of $40 \mathrm{MPa}$ and without ventilation exhibited a similar voids distribution to the one injected with ventilation channels. This suggests that the formation of voids at the WLs with fiber-reinforced thermoplastics is mainly related to the anisotropic shrinkage driven by the induced FO.

\section{8 | Analysis of strain fields with digital image correlation}

Figure 13 presents the strain field in loading direction (ie, flow direction) at a stress level of $\sim 56.5 \mathrm{MPa}$, which corresponds to the onset of failure of the PP40 specimen. A probe line 

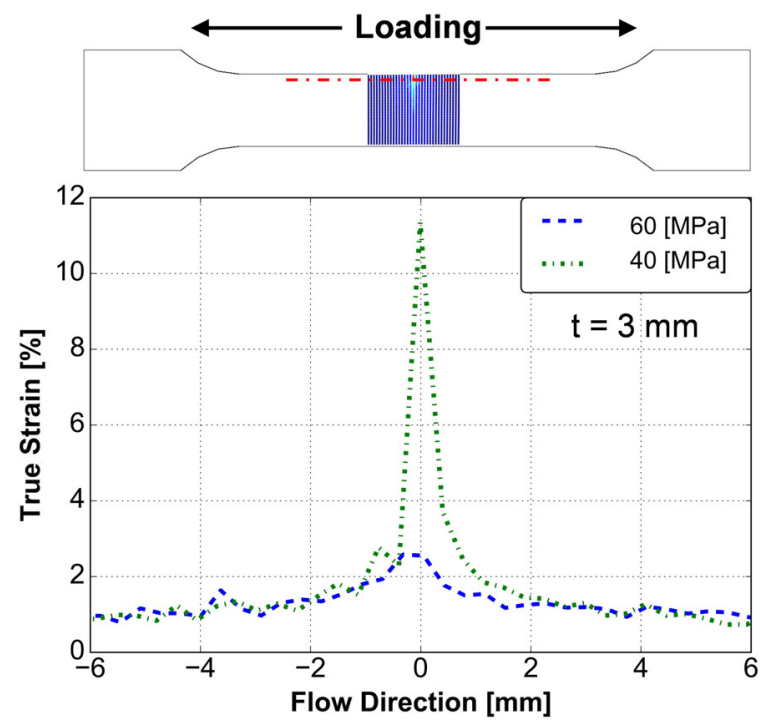

F I G URE 13 True strain profile along flow direction (red pointdashed line) on $3.0 \mathrm{~mm}$ specimens with weld line (0 in the $x$-axis) injection-molded with different packing pressures (40 and $60 \mathrm{MPa}$ ) under similar tension stress (about $56 \mathrm{MPa}$ )

parallel to the loading direction at the location of maximum strain was used for generating the showed profiles.

A strain localization at the WL is clear and can be explained by the FO gradient presented in Figure 5A. In addition, in all specimens analyzed with DIC, the highest strains took place in probe lines located at $\sim 1$ to $2 \mathrm{~mm}$ from the specimen sidewalls. This failure initiation region coincides with a region of complex FO at the WL, which can be shown in Figure 5B.

Next to the sidewalls (at about $1 \mathrm{~mm}$ form the cavity wall), the FO exhibit the most prominent variation in comparison with other regions of the WL plane and would lead to the strain localization at this position of the WL plane. Examination of the fracture surfaces at the WL have also shown a stress-whitening region at this location, which is a sign of micro cracks and ductile failure initiation. ${ }^{[45]}$ The fact that failure takes place exactly at the WL and initiates at regions with steeped changes of FO gradients point out the predominant role of the FO on the WL strength. In fact, no $\mathrm{V}$-notches were observed as showed in Figure 7 and the matrix is able to heal completely at the WL interface according to Figure 3 and rheological measurements of relaxation time.

The elastic modulus was estimated along the frontal WL using the stress data for local strains of $0.05 \%$. The Young's modulus varied along the WL, going from $\sim 3600 \mathrm{MPa}$ at the point of highest deformation to $\sim 4500 \mathrm{MPa}$ at the mid plane of the specimen. The elastic modulus of the matrix (without fibers) is about $2230 \mathrm{MPa}$. The higher values determined at the WL with the composite suggest a reinforcement effect of the fibers at the WL. Away from the WL plane, the estimated
Young's modulus ranged between 7000 and $8000 \mathrm{MPa}$. These changes correlate with the changes in the FO presented in Figure 5. The decrease of the Young's modulus due to the WL has been reported elsewhere. ${ }^{[1-3]}$

In Figure 13, a strain profile of the specimen injected with higher packing pressure at the same stress level $(\sim 56.5 \mathrm{MPa})$ is also shown. In this case, however, the strain localization at the WL is barely perceptible. The reduced strain localization with the PP60 sample shows the impact of the changes in FO at the core of the WL on the macroscopic mechanical behavior. In fact, the increase of FO in flow direction and the smoothing of the FO gradient at the core have led to a larger strength of the specimen in the flow direction.

The previous results point out that the tensile strength at the frontal WL is strongly influenced by the FO gradient showed in Figure 5A. This gradient concentrates the strains and stresses exactly at the WL, where the fibers are mainly oriented in transverse to loading direction.

\section{4 | CONCLUSIONS}

Glass fiber (30 wt\%) reinforced PBT sample were injection molded with a frontal WL. First, measurements of the terminal relaxation time and tensile tests on the unreinforced variant show no influence of the polymer matrix healing. By putting vents in the mold in the WL zone and an adequate holding pressure, V-notches were eliminated. Nevertheless, the frontal WLs of the fiber-reinforced PBT induce a loss more than $50 \%$ of the stress at break and almost $40 \%$ of the strain at break. By measurements of FO thanks to CT scans, the study shows a strong wide gradient of FO in the WL zone. Most of fibers end up parallel to the WL plane whatever the part thickness and therefore these fibers do not play any role in the reinforcement of the material. This explains the reduction of quasi-static tensile strength and strain at failure as well as localization of deformation. The gradient of FO spreads up to around 2 to $3 \mathrm{~mm}$ from the WL plane for both studied thicknesses. The FO changes in thickness direction cause an increase in thickness at the WL due to the increase of $a_{33}$ and then a decrease of shrinkage in thickness direction.

The influence of the packing phase is concentrated at the core region where it forced a reorientation in the flow direction at the WL. If the cavity pressure is not balanced on each side of the WL, then a higher packing pressure reduces the FO gradient at the WL.

The fiber VF witnesses, a decrease at the WL region (3\% of the total mass) but this low variation had no theoretical influence on the elastic properties.

Void formation is nearly unavoidable with frontal WLs because of the influence of the anisotropic FO inducing local 
anisotropic shrinkage behavior. Voids mainly lay at regions at the start of strong FO gradients in the WL region and near the walls. A higher packing pressure has reduced the void VF. As the influence of packing pressure can been clearly explained by the FO variation, it is difficult to quantify the role of voids on mechanical properties at failure under quasistatic tensile loading. Nevertheless, they are absent from the surface of fracture.

Measurements with DIC show the localization of strains at the WLs and the clear influence of the packing pressure on mechanical properties. The failure took place exactly at the WL plane where $a_{11}$ reached a minimum.

Finally, we can conclude that the FO is the dominant factor controlling the mechanical performance and only a good prediction of this FO in frontal WL allow a reliable prediction of mechanical properties in a structural calculation.

\section{ORCID}

Mohamed B. Baradi (D) https://orcid.org/0000-0003-0835-

8819

Gilles Régnier (1D https://orcid.org/0000-0002-1543-1837

\section{REFERENCES}

[1] S. Fellahi, A. Meddad, B. Fisa, B. D. Favis, Adv. Polym. Technol. 1995, 14, 169.

[2] S. C. Malguarnera, A. Manisali, Polym. Eng. Sci. 1981, 21, 586.

[3] R. Seldén, Polym. Eng. Sci. 1997, 37, 205.

[4] S. Hashemi, Express Polym. Lett. 2007, 1, 688.

[5] M. B. Baradi, C. Cruz, G. Régnier, in Proc. of the Europe Africa Conf. 2017 of the Polymer Processing Society (PPS), Dresden, 2017.

[6] B. Fisa, M. Rahmani, Polym. Eng. Sci. 1991, 31, 1330.

[7] C. Kilwon, A. Sunghee, P. Jinbae, P. Chan Eon, H. Jeong, Polym. Eng. Sci. 1997, 37, 1217.

[8] J. K. Kim, J. H. Song, S. T. Chung, T. H. Kwon, Polym. Eng. Sci. 1997, 37, 228.

[9] S. G. Kim, N. P. Suh, Polym. Eng. Sci. 1986, 26, 1200.

[10] K. Tomari, S. Tonogai, T. Harada, H. Hamada, K. Lee, T. Morii, Z. Maekawa, Polym. Eng. Sci. 1990, 30, 931.

[11] A. Vaxman, M. Narkis, A. Siegmann, S. Kenig, Polym. Compos. 1991, $12,161$.

[12] Z. Tadmor, J. App. Polym. Sci. 1974, 18, 1753.

[13] A. Khamsehnezhad, S. Hashemi, J. Mater. Sci. 2008, 43, 6344.

[14] P. Jariyatammanukul, N. Paecheroenchai, P. Pomkajohn, S. Patcharaphun, J. Nat. Sci. 2009, 43, 418.

[15] J. K. Lim, T. Shoji, KSME J. 1993, 7, 173.

[16] F. Prade, F. Schaff, S. Senck, P. Meyer, J. Mohr, J. Kastner, F. Pfeiffer, NDT \& E Int. 2017, 86, 65.

[17] T. Thi, M. Morioka, A. Yokoyama, S. Hamanaka, K. Yamashita, C. Nonomura, Mat. Process. Tech. 2015, 219, 1.

[18] A. Ayadi, H. Nouri, S. Guessasma, F. Roger, Compos. Struct. 2016, 136, 635 .

[19] A. Ayadi, H. Nouri, S. Guessasma, F. Roger, Macromol Mat. Eng. 2016, 301, 907.
[20] C. Hannesschläger, V. Revol, B. Plank, D. Salaberger, J. Kastner, Case Stud NDT\&E 2015, 3, 34.

[21] M. B. Baradi, C. Cruz, T. Riedel, G. Régnier, Polym. Test 2019, 74, 152.

[22] A. Nagura, K. Okamoto, K. Itoh, Y. Imai, D. Shimamoto, Y. Hotta, Compos. Part B Eng. 2015, 76, 38.

[23] D. J. Lee, S. Y. Kim, S. Y. Kim, S. H. Lee, J. R. Youn, Korea Australia Rheol. J. 2010, 22, 95.

[24] A. E. Scott, I. Sinclair, S. M. Spearing, M. N. Mavrogordato, W. Hepples, Comp. Sci. Technol. 2014, 90, 147.

[25] Y. Nikishkov, L. Airoldi, A. Makeev, Comp. Sci. Technol. 2013, $89,89$.

[26] J. E. Little, X. Yuan, M. I. Jones, NDT\&E Int 2012, 46, 122.

[27] G. Titomanlio, S. Piccarolo, G. Marrucci, Polym. Eng. Sci. 1985, 25,91 .

[28] A. Vaxman, M. Narkis, A. Siegmann, S. Kenig, Polym. Comp. 1989, 10, 449.

[29] A. Meddad, B. Fisa, Polym. Eng. Sci. 1995, 35, 893.

[30] P. Shokri, N. Bhatnagar, Phys Proc 2012, 25, 79.

[31] Y. Zhou, P. K. Mallick, Polym. Compos. 2011, 32, 268.

[32] H.-C. Tseng, R.-Y. Chang, C.-H. Hsu, J. Thermoplastic Comp. Mat. 2018, 31, 1204.

[33] C. Cruz, Integrative simulation for assessing the mechanical performance of a weld line on injection moulded thermoplastic parts, presented at 11th World Congress on Computational Mechanics (WCCM XI), 5th European Conf. on Computational Mechanics (ECCM V), 6th European Conf. on Computational Fluid Dynamics (ECFD VI), 2014, 23334.

[34] S. G. Advani, C. L. Tucker III., J. Rheol. 1987, 31, 751.

[35] M. Vincent, T. Giroud, A. Clarke, C. Eberhardt, Polymer 2005, 46, 6719.

[36] Y. C. Kagitci, N. Tarakcioglu, Int. J. Adv. Manuf. Technol. 2016, $85,1125$.

[37] Q. S. Liu, Y. Q. Liu, C. T. Jiang, X. H. Wang, J. Non-Newtonian Fluid Mech. 2019, 263, 140.

[38] T. Mori, K. Tanaka, Acta Metall. Mater. 1973, 21, 571.

[39] J.-M. Kaiser, M. Stommel, Comp. Sci. Technol. 2014, 99, 75.

[40] D. Masato, J. Rathore, M. Sorgato, S. Carmignato, G. Lucchetta, Mat. Design 2017, 132, 496.

[41] M. S. Ingber, A. L. Graham, L. A. Mondy, Z. Fang, Int. J. Multiphase Flow 2009, 35, 270.

[42] T. Dbouk, Rheology of concentrated suspensions and shear-induced migration. PhD thesis, Université Nice Sophia Antipolis NiceFrance, 2011.

[43] T. Nguyen-Chung, G. Mennig, Rheol Acta. 2001, 40, 67.

[44] K.H. Kurth, D. Ramirez, O.N. RudolphEstrada, I. Lopez and T. Osswald, in ANTEC, Conf. Proc. Boston, Mass. 2011, 567.

[45] T. Osswald, G. Menges, Material Science of Polymers for Engineers, 3rd ed., Hanser München, 2012. 